\title{
Flu Season and Trehalose
}

Most of us who are practicing medicine know that we are in a very active flu season. This was brought home to me when last week trying to admit a patient to the hospital from the office. She was a bone marrow transplant patient who had severe diarrhea and dehydration probably secondary to $C$. difficile. Hospital admissions said the patient had to be sent to the Emergency Room because the hospital was full due to the flu epidemic.

Nationwide there has been a dramatic increase in the number of hospitalizations due to influenza over the past week from 13.7 to 22.7 per 100,000 (1). Influenza A(H3N2) has been the most common form of influenza reported this season. These viruses are often linked to more severe illness, especially in children and people age 65 years and older. Fortunately, the CDC also says that the flu cases may be peaking. However, at least 11 to 13 more weeks remain in the influenza season and strains other than $A(H 3 N 2)$ will undoubtedly show up.

Clinicians are reminded that in addition to the flu vaccine for prevention, to begin neuraminidase inhibitor antivirals early. Patients at high risk for complications (elderly, children, pregnant women, patients with chronic diseases such as diabetes, heart disease and asthma) should have treatment begun before laboratory confirmation (2).

Many clinicians have noted an increase in the incidence and severity of $C$. difficile infection over the past 15 years. Because the infection occurs after high dose antibiotics or antibiotics prescribed over a long period of time, it was assumed that this was the cause of the rising rates of infection. However, an alternative explanation was offered by an article appearing last week in Nature (3). The authors showed that two epidemic ribotypes of C. difficile (RT027 and RT078) have acquired unique mechanisms to metabolize low concentrations of the disaccharide trehalose increasing virulence. Trehalose is a sugar widely distributed in nature and used mostly a stabilizing agent in processed foods and products (including influenza vaccine). It was introduced about the same time as the upsurge in C. difficile infection began in the early 2000's.

Richard A. Robbins, MD

Editor, SWJPCC

\section{References}

1. Brooks M. US influenza activity widespread and intense, may be peaking. Medscape. January 12, 2018. Available at: https://www.medscape.com/viewarticle/891265?nlid=120062 3901\&src=wnl newsal rt 180112 MSCPEDIT\&uac=9273DT\&impID=1533392\&faf=1 (accessed 1/14/18).

2. Campbell A. 2016-2017 influenza antiviral recommendations. Medscape. January 9 , 2017. Available at: https://www.medscape.com/viewarticle/873988?src=par cdc stm mscpedt\&faf $=1$ (accessed 1/14/18). 
3. Collins J, Robinson C, Danhof $\mathrm{H}$, et al. Dietary trehalose enhances virulence of epidemic Clostridium difficile. Nature. 2018 Jan 3. [CrossRef] [PubMed] 